J. Lake Sci.(湖泊科学), 2008, 20(6): 715-722

http://www.jlakes.org. E-mail: jlakes@niglas.ac.cn

(C)2008 by Journal of Lake Sciences

\title{
藏南沉错钻孔沉积物金属元素分布特征及其与粒度的关系*
}

\author{
王君波，朱立平 \\ (中国科学院青藏高原研究所, 北京 100085)
}

摘 要: 对藏南沉错 $\mathrm{CC} 1$ 孔 216 个沉积物样品进行了 15 种金属元素含量的测试, 研究金属元素含量的分布特征, 以及与粒度 参数的变化关系. 结果显示: 金属元素的分布特征可分为三组, $\mathrm{K} 、 \mathrm{Na} 、 \mathrm{Mg} 、 \mathrm{Al} 、 \mathrm{Ti} 、 \mathrm{Ba} 、 \mathrm{Cu} 、 \mathrm{Zn} 、 \mathrm{Fe} 、 \mathrm{~Pb} 、 \mathrm{Cr} 、 \mathrm{~V}$ 等 12 种 元素具有较为相似的变化趋势; $\mathrm{Ca}$ 和 $\mathrm{Sr}$ 变化趋势相同; 而 $\mathrm{Mn}$ 与其他任何一种元素都不相似. 元素分布与粒度参数的相关分 析结果表明, $\mathrm{Ca} 、 \mathrm{Ti} 、 \mathrm{~Pb}$ 的变化与沉积物粒度没有明显的关系; $\mathrm{K} 、 \mathrm{Na} 、 \mathrm{Al} 、 \mathrm{Ba} 、 \mathrm{Cu} 、 \mathrm{Fe} 、 \mathrm{Cr} 、 \mathrm{~V}$ 等 8 种元素与沉积物粘土 含量 $(<4 \mu \mathrm{m})$ 呈正相关关系; $\mathrm{Mg} 、 \mathrm{Zn} 、 \mathrm{Mn}$ 与粉砂含量 $(4-63 \mu \mathrm{m})$ 呈正相关关系; 而 $\mathrm{Sr}$ 与砂含量 $(>63 \mu \mathrm{m})$ 呈正相关关系. 本研究中 大部分元素的粒度效应与其他湖泊、海洋等水体沉积物中元素的粒度效应具有一致的结果. 与本岩芯已有的过去 1400 年来的 环境重建资料对比可以发现, 在不同的环境变化阶段, 元素组合特征都与湖区环境状况具有较好的对应性. 其中大部分元素 的含量变化受物源条件即流域风化侵蚀程度的影响, 而 $\mathrm{Ca}$ 含量不受沉积物粒度变化影响, 且与沉积物中碳酸盐含量、 $\mathrm{Sr} / \mathrm{Ba}$ 具有很好的相关性，说明其变化受物源条件影响小，而主要与湖水理化性质、蒸发强度以及湖泊沉积过程有关.

关键词: 湖泊沉积物; 元素分布; 粒度; 环境变化; 沉错

\section{Distribution features of elements in core sediments and their relationship with grain size in Lake Chen Co, southern Tibet}

\section{WANG Junbo \& ZHU Liping}

(Institute of Tibetan Plateau Research, Chinese Academy of Sciences, Beijing 100085, P.R.China)

\begin{abstract}
Altogether 15 metal elements concentration of 216 lake sediment samples from $\mathrm{CC} 1$ core in Chen Co, southern Tibet were measured. Distribution features of all the metal elements and their relationship with grain size parameters was studied. The results showed that all the 15 elements could be divided into three groups according to their distribution features, i.e., 12 elements of $\mathrm{K}, \mathrm{Na}, \mathrm{Mg}, \mathrm{Al}, \mathrm{Ti}, \mathrm{Ba}, \mathrm{Cu}, \mathrm{Zn}$, $\mathrm{Fe}, \mathrm{Pb}, \mathrm{Cr}$ and $\mathrm{V}$ present similar variation trend against depth; $\mathrm{Ca}$ and $\mathrm{Sr}$ had very similar variation trend while Mn was not similar with any other element. The correlation analysis between elements concentration and grain size parameters indicate that the variation of $\mathrm{Ca}$, Ti and $\mathrm{Pb}$ were not influenced by grain size distribution; 8 elements $(\mathrm{K}, \mathrm{Na}, \mathrm{Al}, \mathrm{Ba}, \mathrm{Cu}, \mathrm{Fe}, \mathrm{Cr}, \mathrm{V})$ show positive correlation with clay content $(<4 \mu \mathrm{m})$ of

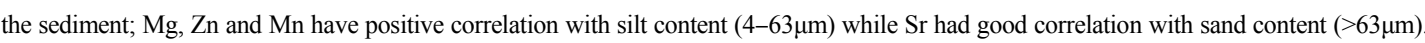
The grain size effects of most elements in this study were coherent with other studies of elements grain size effects in lake sediments and marine sediments. Compared with reconstructed environmental information for the past ca.1400 years from this core, it could be found that the distribution characteristics of elements show rather good correspondence with environmental conditions during different stages. Variations of most elements show influences from sources of materials that is intensity of weathering and erosion in the drainage. However, Ca concentration was not affected by grain size of lake sediments, and performs very good correlation with carbonate content and $\mathrm{Sr} / \mathrm{Ba}$ of sediments, indicating that influence from sources of materials was not the main controlling factor of Ca concentration, while physicochemical features of lake water, evaporation intensity and sedimentary process would probably the major influencing causations.

Keywords: Lake sediment; elements concentration; grain size; environmental changes; Lake Chen Co
\end{abstract}

* 国家自然科学基金项目(40571172, 40701194)、国家重点基础研究发展规划项目(2005CB422002)和中国科学院知识创新工 程方向性项目(KZCX3-SW-339)联合资助. 2008-03-13 收稿; 2008-05-18 收修改稿. 王君波，男，1977 年生，博士; E-mail: wangjb@itpcas.ac.cn. 
在湖泊沉积与环境变化研究中, 沉积物中无机地球化学指标已经成为研究者广泛关注的对象 ${ }^{[1]}$. 其 中，沉积物中元素含量可以用来反映诸如湖泊的营养状况、湖泊古盐度 ${ }^{[2-3]}$ 、人类活动对湖泊的影响 ${ }^{[4-5]}$ 、 流域侵蚀及沉积物来源 ${ }^{[6]}$ 、湖盆演化历史以及湖区环境变化等 ${ }^{[7]}$ 信息.

近年来, 我国学者在湖泊沉积物元素地球化学方面也进行了较多的研究, 除了较少部分研究湖泊的 污染状况外 ${ }^{[8-11]}$, 其他大部分研究都是以环境变化为主要内容, 探讨不同元素含量及元素间比值变化的 环境意义并以此重建研究区环境变化的某一方面. 如对南极部分湖泊沉积物和冰缘沉积物中元素地球化 学特征的研究 ${ }^{[12-15]}$ 、青藏高原部分湖泊沉积物中元素含量及其所反映的环境变化的研究 ${ }^{[16-20]}$ 、以及我国 其他地区如台湾大鬼湖 ${ }^{[21]}$ 和内蒙古岱海 ${ }^{[22]}$ 等研究.

水体沉积物中元素含量的分布受许多因素的影响，如物源区的母岩岩性、矿物组成及风化程度、水 体的理化性质以及各元素本身的活性等. 在沉积过程中, 沉积物的粒度也是影响金属元素含量的一个比 较重要的因素. 对海洋、河流、湖泊等水体沉积物中元素含量与粒度关系的研究都表明，大部分具有粒 度效应的元素通常在细颗粒沉积物中含量较高, 而在粗颗粒沉积物中含量较低 ${ }^{[11,23-31]}$. 这些元素的粒度 效应在某种程度上会对元素的物源效应产生影响 ${ }^{[23,28]}$, 不利于从沉积物元素组成中正确提取古环境变化信 息. 本文以藏南沉错钻孔沉积物为研究对象, 分析了金属元素分布特征与变化规律, 以及元素含量与粒 度组成的关系, 并结合重建的环境变化过程, 对影响沉积物元素分布的湖泊内外界条件进行了初步探讨.

\section{1 研究区概况}

沉错位于藏南羊卓雍错流域范围内, 是一个流域面积约为 $148 \mathrm{~km}^{2}$ 、水面面积 $38 \mathrm{~km}^{2}$ 的封闭湖泊, 湖 面海拔约为 $4420 \mathrm{~m}^{[32]}$. 沉错属于硫酸钠亚型微咸水湖, 1976 年测得湖水 $\mathrm{pH}$ 值为 7.6 , 矿化度为 $1.02 \mathrm{~g} / \mathrm{L}$; 1983-1984 年考察测得湖水 $\mathrm{pH}$ 值为 8.75 , 矿化度为 $1.05 \mathrm{~g} / \mathrm{L} ; 1999$ 年测得 $\mathrm{pH}$ 值为 9.1 , 矿化度为 $1.2 \mathrm{~g} / \mathrm{L}^{[33-34]}$, 可见近 30 年来湖水的 $\mathrm{pH}$ 值和矿化度都在增加, 反映了湖泊处于萎缩状态. 沉错周围山体主 要由三叠系和白严系的变质岩构成 ${ }^{[35]}$, 湖滨周围覆盖有第四纪松散堆积物. 沉错位于温带半干旱气候区 内，根据附近浪卡子气象站的资料，其年平均降水量为 $370 \mathrm{~mm}$, 且 $90 \%$ 以上集中在夏季 (6-9 月份), 年蒸 发量可达 $2070 \mathrm{~mm}$, 年平均气温为 $2.4^{\circ} \mathrm{C}$. 沉错水源补给主要来自大气降水和冰融水, 以枪勇冰川为主要 补给来源的卡鲁雄曲是该湖的唯一人湖河流 ${ }^{[32]}$.

\section{2 材料与方法}

用于分析的 $\mathrm{CC} 1$ 孔沉积岩芯长 $216 \mathrm{~cm}$, 以 $1 \mathrm{~cm}$ 间隔分样, 共获得样品 216 个. 采样点水深 $8 \mathrm{~m}$, 距离 湖岸约 $800 \mathrm{~m}$.

沉积物元素含量 $(\mathrm{K} 、 \mathrm{Na} 、 \mathrm{Ca} 、 \mathrm{Mg} 、 \mathrm{Al} 、 \mathrm{Ti} 、 \mathrm{Sr} 、 \mathrm{Ba} 、 \mathrm{Cu} 、 \mathrm{Zn} 、 \mathrm{Fe} 、 \mathrm{Mn} 、 \mathrm{~Pb} 、 \mathrm{Cr} 、 \mathrm{~V}$ 等 15 种元素 $)$ 利用美国 Baird ICP-2070 型等离子体发射光谱仪进行测定. 沉积物粒度组成利用英国 Malvern 公司生产 的 Mastersizer2000 激光粒度仪分析. 上述试验分析均在中国科学院地理科学与资源研究所完成, 仪器分 析误差小于 $3 \%$.

\section{3 结果与分析}

\section{1 元素含量变化特征}

$\mathrm{CC} 1$ 孔所测得的 15 种元素的含量差别很大, $\mathrm{K} 、 \mathrm{Na} 、 \mathrm{Ca} 、 \mathrm{Mg} 、 \mathrm{Al} 、 \mathrm{Fe} 、 \mathrm{Ti}$ 等这 7 种常量元素含量都 很高. 其中, $\mathrm{Al}$ 含量最高, 平均值超过了 $8 \times 10^{4} \mathrm{mg} / \mathrm{kg}$, 这与 $\mathrm{Al}$ 在地壳中的分布一致; $\mathrm{Ca}$ 的最大含量也达 到了 $16 \times 10^{4} \mathrm{mg} / \mathrm{kg}$. 其余 8 种微量元素的含量都很低, 平均值都在 $10^{3} \mathrm{mg} / \mathrm{kg}$ 以下, $\mathrm{Cu}$ 和 $\mathrm{Pb}$ 的含量最低.

从整个序列来看, 所有元素的含量随深度的变化都较为显著(图 1); 而不同元素含量变化幅度的差异 也很明显. 各元素的变异系数(表 1)说明, 常量元素 $\mathrm{Ca}$ 和微量元素 $\mathrm{Zn}$ 的变异系数最大, 都达到或者超过 了 $40 \%$, 说明它们在整个序列中变化幅度最大; 而常量元素 $\mathrm{Mg}$ 和微量元素 $\mathrm{Ba}$ 的变异系数较小, 都在 $10 \%$ 左右, 说明它们在整个序列中浓度变化较小.

对 15 种元素的含量进行了相关性分析(表 2), 除 $\mathrm{Ca} 、 \mathrm{Sr} 、 \mathrm{Mn}$ 外其他 12 种元素都具有不同程度的相 
关性, 其中 $\mathrm{K}$ 和 $\mathrm{Al}$ 的相关系数最大, 达到 $0.84 . \mathrm{Ca}$ 和 $\mathrm{Sr}$ 的相关系数为 0.90 , 说明这两种元素具有极为一 致的赋存条件以及相似的来源. $\mathrm{Sr}$ 的地球化学特点是容易进人到富含 $\mathrm{Ca}$ 的矿物中, 与 $\mathrm{Ca}$ 互相置换形成 类质同相矿物, 因而决定了二者具有很好的相关性 ${ }^{[11,28]}$. 所有元素中只有 $\mathrm{Mn}$ 与其他元素的相关性最差, 只与 $\mathrm{Fe}$ 具有弱相关, 相关系数为 0.26 , 说明 $\mathrm{Mn}$ 元素具有独特的地球化学性质.

根据以上各元素间变化的相关性分析结果，可以将 $\mathrm{CC} 1$ 孔 15 种元素分为三组，其中 $\mathrm{K} 、 \mathrm{Na} 、 \mathrm{Mg}$ 、 $\mathrm{Al} 、 \mathrm{Ti} 、 \mathrm{Ba} 、 \mathrm{Cu} 、 \mathrm{Zn} 、 \mathrm{Fe} 、 \mathrm{~Pb} 、 \mathrm{Cr} 、 \mathrm{~V}$ 等 12 种元素为一组，垂向上具有相似的变化趋势; $\mathrm{Ca}$ 和 $\mathrm{Sr}$ 为一 组, 其变化趋势也一致, 且与第一组元素的变化规律相反; $\mathrm{Mn}$ 单独为一组, 其变化规律与其他元素都不 相同.

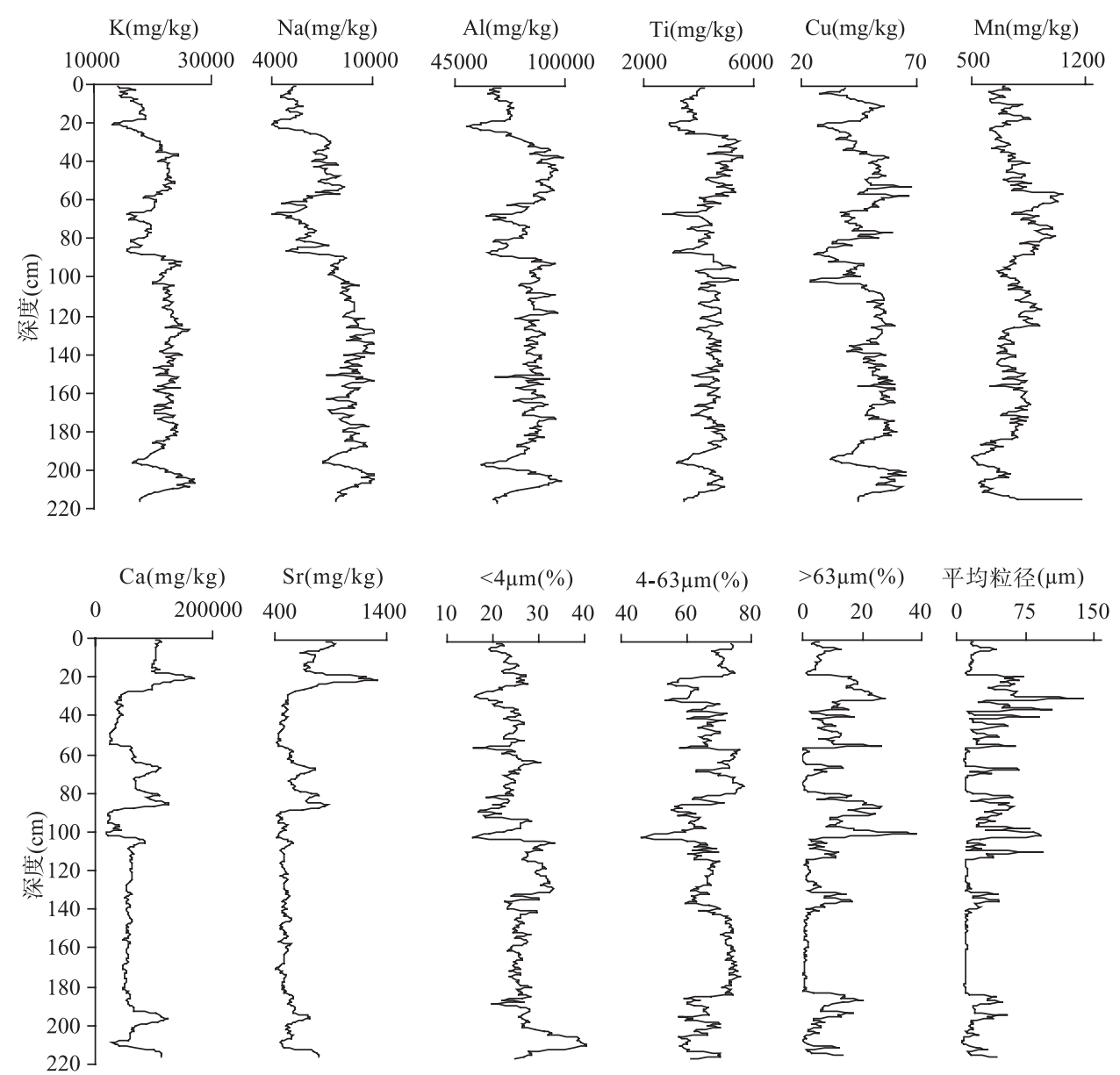

图 $1 \mathrm{CC} 1$ 孔部分元素含量及粒度参数变化

Fig.1 Variation of some elements and grain size parameter in $\mathrm{CC} 1$ core

\section{2 元素含量与粒度的关系}

从 $\mathrm{CC} 1$ 孔粒度数据中选取了 $\mathrm{D}[4,3]$ 和 $<4 \mu \mathrm{m} 、 4-63 \mu \mathrm{m} 、>63 \mu \mathrm{m}$ 的百分含量等 4 个粒度参数，其中 $\mathrm{D}[4,3]$ 代表样品的体积加权平均粒径, 由粒度仪测量软件直接计算得出; 根据乌登-温德沃思粒级分类方法 ${ }^{[36]}$, 后三个不同粒级分别可以代表样品中粘土、粉砂、砂的百分含量. 分别计算了 15 种元素与 4 个粒度参数 的相关系数见表 2 .

粒度参数 $\mathrm{D}[4,3]$ 与 $<4 \mu \mathrm{m}$ 和 $4-63 \mu \mathrm{m}$ 的百分含量存在负相关关系(相关系数分别为 -0.47 和 -0.72 ), 而 
和 $>63 \mu \mathrm{m}$ 的百分含量具有很高的正相关关系, 相关系数为 0.88 , 这说明 $\mathrm{D}[4,3]$ 主要代表了粗颗粒粒径的 百分含量.

表 $1 \mathrm{CC} 1$ 孔 15 种元素的部分统计量 $(\mathrm{mg} / \mathrm{kg})$

Tab.1 Some statistics of 15 elements of $\mathrm{CC} 1 \mathrm{core}(\mathrm{mg} / \mathrm{kg})$

\begin{tabular}{lccccccccccccccc}
\hline 统计量 & $\mathrm{K}$ & $\mathrm{Na}$ & $\mathrm{Ca}$ & $\mathrm{Mg}$ & $\mathrm{Al}$ & $\mathrm{Ti}$ & $\mathrm{Sr}$ & $\mathrm{Ba}$ & $\mathrm{Cu}$ & $\mathrm{Zn}$ & $\mathrm{Fe}$ & $\mathrm{Mn}$ & $\mathrm{Pb}$ & $\mathrm{Cr}$ & $\mathrm{V}$ \\
\hline 平均值 & 21077 & 7643 & 65482 & 10287 & 80609 & 4365 & 562 & 411 & 48 & 107 & 44641 & 767 & 43 & 100 & 140 \\
最大值 & 27252 & 10303 & 168455 & 12908 & 98802 & 5627 & 1319 & 547 & 67 & 378 & 69052 & 1572 & 71 & 197 & 181 \\
最小值 & 13118 & 3876 & 19424 & 7734 & 50425 & 2650 & 407 & 297 & 24 & 35 & 28459 & 497 & 17 & 38 & 83 \\
标准差 & 2835 & 1554 & 27863 & 1008 & 9635 & 535 & 144 & 43 & 9 & 43 & 6273 & 132 & 11 & 24 & 19 \\
变异系数(\%) & 13.4 & 20.3 & 42.5 & 9.8 & 12.0 & 12.2 & 25.7 & 10.5 & 17.9 & 40.0 & 14.1 & 17.3 & 25.8 & 24.3 & 13.7 \\
\hline
\end{tabular}

表 $2 \mathrm{CC} 1$ 孔 15 种元素及部分粒度参数之间的相关系数*

Tab.2 Correlation coefficients of 15 elements and some grain size parameters of CC1 core

\begin{tabular}{|c|c|c|c|c|c|c|c|c|c|c|c|c|c|c|c|c|c|c|c|}
\hline & K & $\mathrm{Na}$ & $\mathrm{Ca}$ & $\mathrm{Mg}$ & $\mathrm{Al}$ & $\mathrm{Ti}$ & $\mathrm{Sr}$ & $\mathrm{Ba}$ & $\mathrm{Cu}$ & $\mathrm{Zn}$ & $\mathrm{Fe}$ & $\mathrm{Mn}$ & $\mathrm{Pb}$ & $\mathrm{Cr}$ & V & $\mathrm{D}[4,3]$ & $<4 \mu \mathrm{m}$ & $4-63 \mu \mathrm{m}>$ & $>63 \mu \mathrm{m}$ \\
\hline K & 1.00 & & & & & & & & & & & & & & & & & & \\
\hline $\mathrm{Na}$ & 0.81 & 1.00 & & & & & & & & & & & & & & & & & \\
\hline $\mathrm{Ca}$ & -0.77 & -0.58 & 31.00 & & & & & & & & & & & & & & & & \\
\hline $\mathrm{Mg}$ & 0.63 & 0.45 & -0.55 & 1.00 & & & & & & & & & & & & & & & \\
\hline $\mathrm{Al}$ & 0.84 & 0.63 & -0.83 & 0.67 & 1.00 & & & & & & & & & & & & & & \\
\hline $\mathrm{Ti}$ & 0.65 & 0.49 & -0.75 & 0.55 & 0.73 & 1.00 & & & & & & & & & & & & & \\
\hline $\mathrm{Sr}$ & -0.79 & -0.67 & 0.90 & -0.56 & -0.80 & -0.68 & 1.00 & & & & & & & & & & & & \\
\hline $\mathrm{Ba}$ & 0.78 & 0.45 & -0.66 & 0.56 & 0.76 & 0.66 & -0.58 & 1.00 & & & & & & & & & & & \\
\hline $\mathrm{Cu}$ & 0.67 & 0.52 & -0.40 & 0.68 & 0.61 & 0.41 & -0.52 & 0.64 & 1.00 & & & & & & & & & & \\
\hline $\mathrm{Zn}$ & 0.31 & 0.26 & -0.34 & 0.36 & 0.33 & 0.23 & -0.36 & 0.19 & 0.41 & 1.00 & & & & & & & & & \\
\hline $\mathrm{Fe}$ & 0.64 & 0.44 & -0.65 & 0.48 & 0.65 & 0.57 & -0.67 & 0.64 & 0.56 & 0.32 & 1.00 & & & & & & & & \\
\hline $\mathrm{Mn}$ & -0.09 & -0.14 & 0.08 & 0.07 & 0.00 & -0.02 & 0.04 & -0.08 & 0.11 & 0.09 & 0.26 & 1.00 & & & & & & & \\
\hline $\mathrm{Pb}$ & 0.54 & 0.29 & -0.56 & 0.45 & 0.60 & 0.58 & -0.55 & 0.58 & 0.41 & 0.20 & 0.51 & 0.08 & 1.00 & & & & & & \\
\hline $\mathrm{Cr}$ & 0.53 & 0.64 & -0.29 & 0.31 & 0.36 & 0.32 & -0.41 & 0.27 & 0.52 & 0.25 & 0.32 & 0.06 & 0.21 & 1.00 & & & & & \\
\hline $\mathrm{V}$ & 0.75 & 0.64 & -0.58 & 0.45 & 0.68 & 0.62 & -0.67 & 0.59 & 0.60 & 0.26 & 0.58 & 0.05 & 0.47 & 0.51 & 1.00 & & & & \\
\hline $\mathrm{D}[4,3]$ & -0.28 & -0.27 & 0.06 & -0.28 & -0.21 & 0.00 & 0.23 & -0.20 & -0.55 & -0.21 & -0.22 & $-0.15-$ & -0.08 & -0.40 & -0.34 & 1.00 & & & \\
\hline$<4 \mu \mathrm{m}$ & 0.50 & 0.45 & -0.06 & 0.16 & 0.24 & 0.00 & -0.19 & 0.42 & 0.53 & 0.04 & 0.27 & -0.12 & 0.04 & 0.45 & 0.47 & -0.47 & 1.00 & & \\
\hline $4-63 \mu \mathrm{m}$ & 0.01 & -0.06 & 0.01 & 0.31 & 0.11 & 0.01 & -0.13 & -0.01 & 0.42 & 0.24 & 0.10 & 0.31 & 0.12 & 0.21 & 0.15 & -0.72 & -0.05 & 1.00 & \\
\hline$>63 \mu \mathrm{m}$ & -0.30 & -0.21 & 0.03 & -0.36 & -0.23 & -0.01 & 0.22 & -0.24 & -0.66 & -0.22 & -0.24 & $-0.19-$ & -0.13 & -0.43 & -0.40 & 0.88 & -0.54 & -0.82 & 1.00 \\
\hline
\end{tabular}

* 相关系数绝对值大于 0.19 时, 在 0.01 水平显著相关; 大于 0.15 时, 在 0.05 水平显著相关.

$\mathrm{CC} 1$ 孔沉积岩芯中元素含量与粒度组成的变化规律可分为四种类型. $\mathrm{Ca} 、 \mathrm{Ti} 、 \mathrm{~Pb} 3$ 种元素与所有粒 度参数都没有显示出相关性, 即这 3 种元素的含量变化不受沉积物粒度组成变化的影响, 说明这 3 种元 素可以以不同的形式存在于任何 1 种粒级的颗粒物中或者来源较为复杂.

$\mathrm{K} 、 \mathrm{Na} 、 \mathrm{Al} 、 \mathrm{Ba} 、 \mathrm{Cu} 、 \mathrm{Fe} 、 \mathrm{Cr} 、 \mathrm{~V}$ 等元素含量的变化都与沉积物中粘土含量的变化呈一致性，而与砂 的含量变化呈反相关关系. 说明这些元素多赋存在粘土矿物中, 随细粒沉积物进人湖泊. 在这 8 种元素中, 以 $\mathrm{Cu}$ 元素与粒度参数的相关性最高, 与粘土、粉砂、砂的相关系数分别为 $0.53 、 0.42$ 和-0.66(图 2). 

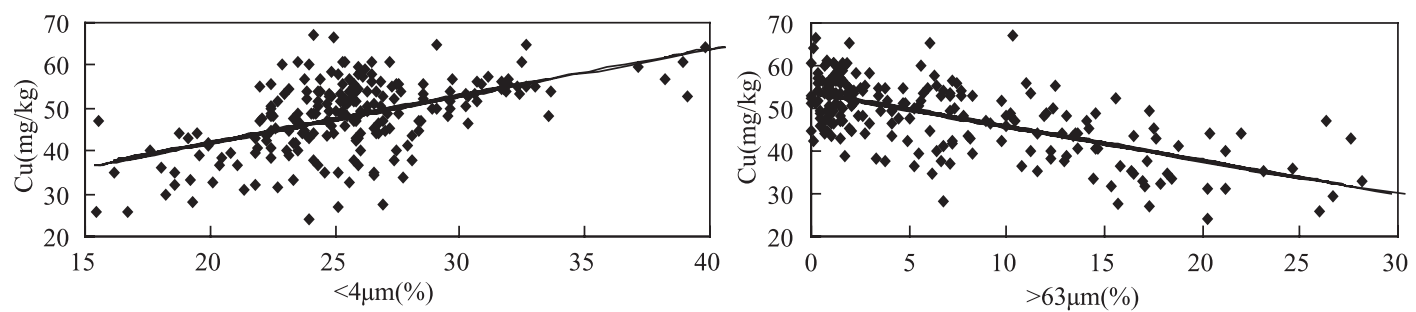

图 $2 \mathrm{CC} 1$ 孔中 $\mathrm{Cu}$ 元素含量与粒度参数之间的变化关系

Fig.2 The relationship between concentration of $\mathrm{Cu}$ and some grain size parameters in $\mathrm{CC} 1$ core

$\mathrm{Mg} 、 \mathrm{Zn}$ 和 $\mathrm{Mn}$ 这 3 种元素的含量与粉砂粒级的含量呈典型正相关, 尤其是 $\mathrm{Mn}$ 元素，与粘土、砂的 含量都呈负相关, 说明这 3 种元素更多的存在于粉砂粒级的颗粒物中进人湖泊. 但是其相关系数都不是 很高(分别为 $0.31 、 0.24$ 和 0.31 ), 说明其含量受沉积物粒度的影响较弱.

$\mathrm{Sr}$ 是唯一一个与砂含量呈正相关, 而与粘土、粉砂含量呈负相关的元素, 说明 $\mathrm{Sr}$ 更容易随着粗颗粒 沉积物进入湖泊, 但较小的相关系数 $(r=0.22)$ 说明 $\mathrm{Sr}$ 含量变化受沉积物粒度变化的影响较小.

\section{4 讨论与结论}

自然界中不同粒径的颗粒具有不同的金属元素含量, 沉错沉积岩芯中大部分元素都和细粒沉积物含

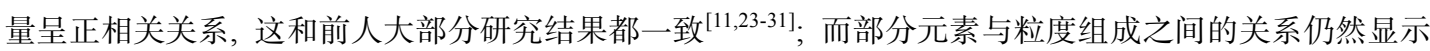
出较大的差异. 如 $\mathrm{Na}$ 元素, 对太湖沉积物的研究结果显示 $\mathrm{Na}$ 与粗颗粒 $(>64 \mu \mathrm{m})$ 百分含量相关最大, 而与 细颗粒 $(<4 \mu \mathrm{m})$ 含量呈显著负相关 ${ }^{[30]}$; 而对渤海湾潮间带沉积物的研究则显示 $\mathrm{Na}$ 是唯一一个不受粒度控 制的元素, 并认为其特殊的地球化学行为也许是沉积物样品受到海盐污染造成的 ${ }^{[27]}$; 南黄海沉积物中 $\mathrm{Na}$ 的粒度效应与本研究结果一致 ${ }^{[28]}$. 不同研究区的水体中 $\mathrm{Na}$ 元素与沉积物粒度的关系的差异可能主要反 映了沉积物来源的不同，即水体所在区域母岩性质的差异.

$\mathrm{CC} 1$ 孔沉积物中, $\mathrm{Ca} 、 \mathrm{Ti} 、 \mathrm{~Pb}$ 没有显示出与粒度的相关性, 这也与南黄海沉积物的结果一致 ${ }^{[28]}$, 而在 渤海湾沉积物中三者都与细粒沉积物呈较高的正相关关系 ${ }^{[27]}$; 在太湖沉积物中 $\mathrm{Ca}$ 和 $\mathrm{Pb}$ 分别和细粒和中 间粒级颗粒相关最显著 ${ }^{[30]}$; 而大汶口潮间带沉积物中 $\mathrm{Pb}$ 的含量与沉积物粒径间没有相关关系 ${ }^{[31]} . \mathrm{CC} 1$ 孔 中, $\mathrm{Sr}$ 是唯一一个与粗颗粒沉积物呈正相关的元素, 这一结果与渤海湾沉积物相同 ${ }^{[27]}$, 而太湖沉积物中 $\mathrm{Sr}$ 表现为与细粒沉积物呈正相关 ${ }^{[30]}$. $\mathrm{Sr}$ 受沉积物粒度变化影响是最弱的, 而 $\mathrm{Ca}$ 与 $\mathrm{Sr}$ 具有很好的相似性, 且 $\mathrm{Ca}$ 与沉积物粒度变化并无相关性, 因而可以认为作为具有相似化学性质的 $\mathrm{Sr}$ 和 $\mathrm{Ca}$, 其含量变化在沉 积物中受粒度的控制效应很小，它们主要受物源控制 ${ }^{[28]}$.

从以上比较可以看出, 粒度效应在不同区域不同沉积环境中表现较为复杂, 金属元素的粒度效应除 了取决于元素本身的地球化学性质之外，还受到流域母质岩性特征等物源的影响.

对于沉错 $\mathrm{CC} 1$ 孔，已有的研究已利用 ${ }^{210} \mathrm{~Pb}$ 和 ${ }^{137} \mathrm{Cs}$ 方法对其进行了定年，并利用磁学参数、粒度参 数与地球化学指标等对湖区近 1400 年来的环境演化状况进行了研究 ${ }^{[37-39]}$. 图 3 对几种元素含量、部分元 素比值及粒度参数进行了对比, 并从时间尺度上划分了几个阶段. 其中 $\mathrm{K}$ 的含量可以代表大部分与粘土 含量具有相似变化趋势的元素, $\mathrm{Ca}$ 的含量代表与粒度没有相关性的元素, 而 $\mathrm{Mn}$ 的含量代表与粉砂具有 相关性的元素. 其中 $\mathrm{Ca}$ 的含量和通过普通化学方法测定的 $\mathrm{CaCO}_{3}$ 的含量以及 $\mathrm{Sr} / \mathrm{Ba}$ 的变化趋势十分相似, 其相关系数分别为 0.96 和 0.90 , 由于在湖泊沉积物中后二者都被认为是湖区环境有效湿度及湖水水量变 化的有效代用指标 ${ }^{[40-42]}$, 因而本研究中 $\mathrm{CC} 1$ 孔沉积物中 $\mathrm{Ca}$ 元素的含量变化也可以作为对沉错地区近 1400 年来干湿变化的响应指标.

随着不同时期环境状况的差异, $\mathrm{CC} 1$ 孔沉积物中元素含量变化剧烈, 大致可以以 820AD、1350AD 和 1900AD 为界分为 4 个阶段(图 3). 其中约 820AD 之前, 粒度变化较为显著, 且频率分布曲线多为双峰或 多峰 ${ }^{[38]}$, 说明沉积环境复杂, 环境波动剧烈; 磁学指标显示此阶段前期(740AD 之前)为暖期. 从 CC1 孔沉 
积物的元素组合来看, 这一阶段各元素的含量也出现了较大波动, 是对湖区环境状况的良好响应. 特别 是在约 740AD 之前的暖期，冰川融水补给增加导致地表径流增强从而使进人湖泊的碎屑增加, $\mathrm{K} 、 \mathrm{Mn}$ 等 元素的含量都较高; 而有效湿度的降低则使 $\mathrm{Ca}$ 离子浓度处于较低的水平.

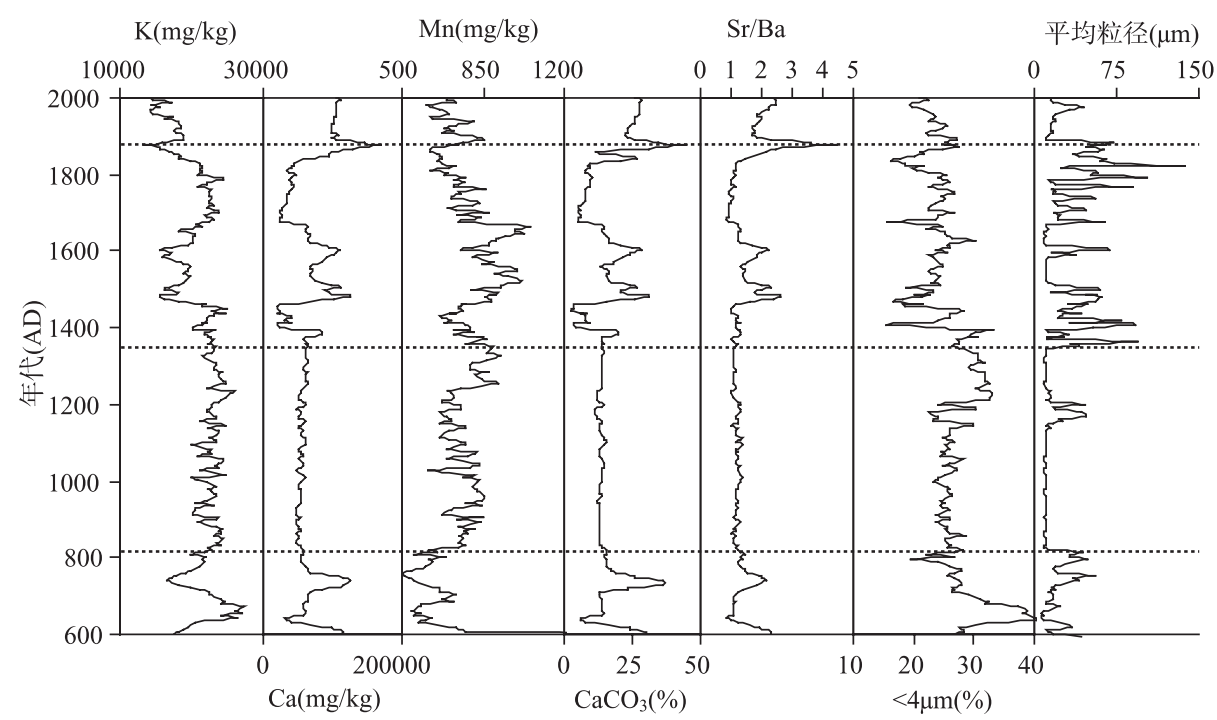

图 $3 \mathrm{CC} 1$ 孔近 1400 年来部分元素含量和粒度变化对比

Fig. 3 Some elements and grain size variation in the past ca.1400 years in CC1 core

在约 820-1350AD 之间, 这一时期对应于 “中世纪温暖期” , 各环境指标都变化平稳, 沉积物粒度组 成中以粘土成分为主, 平均粒径较小, 说明湖泊处于高湖面的稳定期, 湖区温暖湿润植被发育良好, 流 域侵蚀风化进入湖泊的物质以粘土和粉砂粒级的颗粒为主. 从元素组合来看, $\mathrm{K}$ 等亲岩元素多富集于粘 土矿物中随地表径流中进入湖泊, 因而其含量都较高; 暖湿的环境条件使湖泊中 $\mathrm{CaCO}_{3}$ 沉淀作用减弱, 因而这一阶段 $\mathrm{Ca}$ 的含量较低且变化不大. 值得指出的是, 在约 1150-1200AD之间, 粒度指标指示了一次 快速变化的过程, 可能反映了一个较短的人湖水流增强的时段 ${ }^{[38]}$, 但是这一时段在所有的元素含量变化 曲线上都没有得到显示，其原因也许是随碎屑进入湖泊的元素在经过沉积物颗粒的吸附作用后掩盖了部 分物源信息.

在约 1350-1900AD之间，沉错湖区环境又处于剧烈变化之中，沉积物粒度组成中粘土含量显著降低， 砂和粉砂含量明显增加, 特别是在约 1690-1900AD 之间温度降低, 蒸发较弱, 砂含量增加都说明此时地 表流水增强, 湖区主要处于寒冻风化作用下, 是小冰期的冷期 ${ }^{[37,39]}, \mathrm{CC} 1$ 孔的元素变化特征也显示了与上 一阶段的不同, 各元素含量出现了剧烈波动, 其中 $\mathrm{K}$ 和 $\mathrm{Ca}$ 显示了完全相反的变化规律. $\mathrm{K}$ 含量较低且与 粘土的含量显示出较好的相关性, 而 Mn 的含量此阶段最高, 说明强烈的地表流水将较粗的颗粒物带人 湖泊, 造成富集于粗颗粒的 $\mathrm{Mn}$ 元素在沉积物中含量的增加. 此阶段沉错的补给增加使湖区有效湿度大 大增加, 从而使沉积物中 $\mathrm{Ca}$ 含量整体上处于很低的水平.

约 $1900 \mathrm{AD}$ 以来的 100 年左右, 湖区环境处于暖干状态, 沉积物粒度组成以粗颗粒为主, 粘土颗粒含 量不高, 反映地表流水较强, 风化侵蚀作用强烈, 然而大量粗颗粒物质进入湖泊在一定程度上稀释了 $\mathrm{K}$ 元 素的含量，致使其含量基本上处于整个序列的最低值，温暖的环境条件虽然有助于冰川融水的增加，然 而可能还不足以弥补蒸发的加强，因而在暖干的气候条件下较强的蒸发作用导致 $\mathrm{Ca}$ 含量较高.

通过以上分析可以看出：Ca 含量不受沉积物粒度变化控制，而应该主要受湖水的理化性质、蒸发作 用及沉积过程控制, 因而可以作为湖区环境变化的有效指标; 在所有元素中, $\mathrm{Ca}$ 的变异系数是最大的, 也说明与其他元素相比, 影响 $\mathrm{Ca}$ 沉积的条件是最复杂的. $\mathrm{K} 、 \mathrm{Na} 、 \mathrm{Al} 、 \mathrm{Mn}$ 等元素因其赋存条件不同而与 
沉积物粒度呈现一定的相关性, 结合湖区环境状况分析, 这些元素的变化主要反映了流域的侵蚀风化程 度, 因而沉错沉积物元素的变化主要受物源因素控制.

\section{5 参考文献}

[1] Boyle JF. Inorganic geochemical methods in palaeolimnology. In: Last WM, Smol JP eds. Tracking environmental change using lake sediments. Volume 2: physical and geochemical methods. Dordrecht, the Netherlands: Kluwer Academic Publishers, 2001: 83-141.

[2] Machereth FJH. Some chemical observations on post-glacial lake sediments. Phil Trans R Sco Lond, 1966, B250: $165-213$.

[3] Engstrom DR, Wright Jr HE. Chemical stratigraphy of lake sediments as a record of environmental change. In: Haworth EY, Lund JWG eds. Lake sediments and environmental history. Leicester: Leicester University Press, 1984: 11-68.

[4] Aston SR, Bruty D, Chester R et al. Mercury in lake sediments: a possible indicator of technological growth. Nature, 1973, 241: $450-451$.

[5] Punning JM, Boyle JF, Alliksaar T et al. Human impact on the history of Lake Nômmejärv, NE Estonia: a geochemical and palaeobotanical study. The Holocene, 1997, 7: 91-99.

[6] Boyle JF, Rose NL, Bennion H et al. Environmental impact in the Jianghan Plain: evidence from lake sediments. Wat Air Soil Pollut, 1999, 112: 21-40.

[7] Koinig KA, Shotyk W, Lotter AF et al. 9000 years of geochemical evolution of lithogenic major and trace elements in the sediments of an alpine lake-the role of climate, vegetation, and land-use history. Journal of Paleolimnology, 2003, 30: 307-320.

[8] 董德明, 路永正, 李 鱼等. 吉林省部分河流与湖泊表层沉积物中重金属的分布规律. 吉林大学学报(地球科学版), 2005, 35(1): 91-96.

[9] 戴秀丽, 孙 成. 太湖沉积物中重金属污染状况及分布特征探讨. 上海环境科学, 2001, 20(2): 71-74.

[10] 刘恩峰, 沈 吉, 朱育新. 西太湖沉积物污染的地球化学记录及对比研究. 地理科学, 2005, 25(1): 102-107.

[11] 杨丽原, 沈 吉, 张祖陆等. 近四十年来山东南四湖环境演化的元素地球化学记录. 地球化学, 2003, 32(5): 453-460.

[12] 孙立广, 谢周清, 赵俊琳. 南极阿德雷岛湖泊沉积物 $\mathrm{Sr} / \mathrm{Ba}$ 与 $\mathrm{B} / \mathrm{Ga}$ 比值特征. 海洋地质与第四纪地质, 2000, 20(4): 43-47.

[13] 李小梅, 沙晋明, 赵俊琳. 南极菲尔德斯半岛湖泊沉积物元素地球化学特征. 成都理工大学学报(自然科学版), 2005, 32(5): 460-465.

[14] 余素华, 郑洪汉, 陈肖柏等. 西南极乔治王岛长城站区晚第四纪燕窝湖岩芯元素地球化学特征. 南极研究, 1992, 4(3): 31-37.

[15] 刘晓东, 孙立广, 谢周清等. 南极纳尔逊冰缘沉积物元素地球化学特征及其化学风化作用研究. 第四纪研究, 2002, 22(5): 483-491.

[16] 吴艳宏, 李世杰, 夏威岗. 可可西里苟仁错湖泊沉积物元素地球化学特征及其环境意义. 地球科学与环境学报, 2004, 26(3): 64-68.

[17] 陈诗越, 王苏民, 金章东等. 青藏高原中部湖泊沉积物中 $\mathrm{Zr} / \mathrm{Rb}$ 值及其环境意义. 海洋地质与第四纪地质, 2003, 23(4): 35-38.

[18] 余素华, 朱照宇, 李炳元等. 23 万年来青藏高原甜水海湖岩心铁元素的气候记录刍议. 海洋地质与第四纪地质, 1998 , 18(3): 63-70.

[19] 陈 玲, 朱立平, 张青松. 近 150a 来南红山湖的地球化学特征及环境意义. 地理科学, 2002, 22(1): 39-42.

[20] 朱立平, 王君波, 陈 玲等. 藏南沉错湖泊沉积多指标揭示的 2 万年以来环境变化. 地理学报, 2004, 59(4): 514-524.

[21] 罗建育, 陈镇东. 台湾大鬼湖沉积物元素分布所反映的古环境意义. 湖泊科学, 1998, 10(3): 13-18.

[22] 金章东, 王苏民, 沈 吉等. 小冰期弱化学风化的湖泊沉积记录. 中国科学(D 辑), 2001, 31(3): 221-225.

[23] 赵一阳, 喻德科. 黄海沉积物地球化学分析. 海洋与湖沼, 1983, 14(5): 432-446.

[24] 陈静生, 王飞越, 陈江麟. 论小于 $63 \mu \mathrm{m}$ 粒级作为水体颗粒物重金属研究介质的合理性及有关粒级转换模型研究. 环境 科学学报, 1994, 14(4): 419-425.

[25] 陈静生, 王飞越, 宋吉杰等. 中国东部河流沉积物中重金属含量与沉积物主要性质的关系. 环境化学, 1996, 15(1): 8-14. 
[26] 陈静生, 洪 松, 王立新等. 中国东部河流颗粒物的地球化学性质. 地理学报, 2000, 55(4): 417-427.

[27] Zhang CS, Wang LJ, Li GS et al. Grain size effect on multi-element concentrations in sediments from the intertidal flats of Bohai Bay, China. Applied Geochemistry, 2002, 17: 59-68.

[28] 杜德文, 石学法, 孟宪伟等. 黄海沉积物地球化学的粒度效应. 海洋科学进展, 2003, 21(1): 78-82.

[29] 孙惠民, 何 江, 吕昌伟等. 乌梁素海沉积物中有机质和全氮含量分布特征. 应用生态学报, 2006, 17(4): 620-624.

[30] 刘恩峰, 沈 吉, 朱育新. 沉积物金属元素变化的粒度效应——以太湖沉积岩芯为例. 湖泊科学, 2006, 18(4): 363-368.

[31] 秦延文, 孟 伟, 郑丙辉等. 渤海湾天津段潮间带沉积物柱状样重金属污染特征. 环境科学, 2006, 27(2): 267-273.

[32] 关志华, 陈传友, 区裕雄等. 西藏河流与湖泊. 北京: 科学出版社, 1984: 115-215.

[33] 王苏民, 窦鸿身. 中国湖泊志. 北京: 科学出版社, 1998: 438.

[34] 羊向东, 王苏民, Kamenik C 等. 藏南沉错钻孔硅藻组合与湖水古盐度定量恢复. 中国科学(D 辑), 2003, 33(2): 163-169.

[35] 文世宣, 章炳高, 王义刚等. 西藏地层. 北京: 科学出版社, 1984: 109-124.

[36] 李蔩生, 孙永传. 碎屑岩沉积相和沉积环境. 北京: 地质出版社, 1986: 1-280.

[37] Zhu LP, Zhang PZ, Xia WL et al. 1400-yrs cold/warm fluctuations reflected by environmental magnetism of a lake sediment core from the Chen Co, southern Tibet, China. Journal of Paleolimnology, 2003, 29(4): 391-401.

[38] 王君波, 朱立平. 藏南沉错沉积物的粒度特征及其古环境意义. 地理科学进展, 2002, 21(5): 459-467.

[39] 王君波, 朱立平. 藏南沉错沉积物有机质 $\delta^{13} \mathrm{C}$ 对湖区环境冷暖变化的响应. 海洋地质与第四纪地质, 2007, 27(2): 113-120.

[40] 李世杰, 区荣康, 朱照宇等. 24 万年来西昆仑山甜水海湖岩芯碳酸盐含量变化与气候环境演化. 湖泊科学, 1998, 10(2): 58-65.

[41] 朱立平, 陈 玲, 李炳元等. 西昆仑山南红山湖沉积反映的过去 150 年湖区环境变化. 中国科学(D 辑), 2001, 31(7): 601-607.

[42] 鞠建廷, 朱立平, 汪 勇等. 藏南普莫雍错流域水体离子的组成与空间分布及其环境意义初步研究. 湖泊科学, 2008, 20(5): 591-599. 